Article

\title{
Agricultural Commodities and Crude Oil Prices: An Empirical Investigation of Their Relationship
}

\author{
Eleni Zafeiriou ${ }^{1, *}$, Garyfallos Arabatzis ${ }^{2}$, Paraskevi Karanikola ${ }^{2}$, Stilianos Tampakis ${ }^{2}$ (i) and \\ Stavros Tsiantikoudis 2 (1) \\ 1 Department of Agricultural Development, Democritus University of Thrace, Xanthi 671 00, Greece \\ 2 Department of Forestry and Management of the Environment and Natural Resources, Democritus \\ University of Thrace, Xanthi 671 00, Greece; garamp@fmenr.duth.gr (G.A.); pkaranik@fmenr.gr (P.K.); \\ stampaki@fmenr.duth.gr (S.T.) \\ * Correspondence: ezafeir@agro.duth.gr
}

Received: 11 March 2018; Accepted: 11 April 2018; Published: 16 April 2018

\begin{abstract}
Within the last few decades, the extended use of biodiesel and bioethanol has established interlinkages between energy markets and agricultural commodity markets. The present work examines the bivariate relationships of crude oil-corn and crude oil-soybean futures prices with the assistance of the ARDL cointegration approach. Our findings confirm that crude oil prices affect the prices of agricultural products used in the production of biodiesel, as well as of ethanol, validating the interaction of energy and agricultural commodity markets. The practical value of the present work is that the findings provide policy makers with insight into the interlinkages between agricultural and energy markets to promote biodiesel or bioethanol by affecting crude oil prices. The novelty of the present work stands on the use of futures prices that incorporate all available information and thus are more appropriate to identify supply and demand shocks and price spillovers than real prices. Finally, the period of study includes extremely low, as well as extremely high, crude oil prices and the results illustrate that biofuels cannot be substituted for crude oil and protect economies from energy volatility.
\end{abstract}

Keywords: soybean; corn; crude oil; energy markets; sustainable development

\section{Introduction}

Climate change, the volatility of crude oil prices, the issue of food security, and the global economic crisis have motivated decision-makers, industries, and economic agents involved in the biofuel sector to expand the use and production of biofuels [1]. However, persistent low crude oil prices since 2014 seem to be an impediment to this effort.

The expansion of biofuels has established interlinkages between energy markets and agricultural markets given that corn is used to produce biofuels and soybean is used to produce biodiesel [2].

The major objectives of a national policy for a healthy economy are food security, limitations on GHG emissions, economic growth, and compliance with objectives set by the Kyoto protocol. The biofuel market is an artificial market, the function of which is regulated by state [3,4]. The role of this market has become crucial in economic growth, satisfying the priority of sustainability. On the other hand, the alternative use of agricultural products such as corn and soybean (either for food or to produce biofuels) is leading to indirect land use change and to a deterioration in the problem of climate change.

Therefore, given the use of the two agricultural products in the production of biofuels, as well as their use for food, the existing mutual interdependencies reflect the mutual market interdependencies. Increasing prices of corn may well be attributed to the dominant conditions in the food market that 
are also providing an indication for the interdependency of corn price with biofuels [5]. The specific relationship is related to many factors including the country, the model, and the dimension of time [6].

On the other hand, given that corn and soybean evolved into a major motor-fuel energy source, a close relationship between corn (the major feedstock for ethanol) and soybean production (major input in biodiesel) with crude oil, the main feedstock for gasoline production, may be an expected result. The data used extends from late 2004 through mid-2008, when rapid expansion of the ethanol industry was occurring, which is the reason for which the relationship has been mainly established [2,7].

Most of issues mentioned above are reflected in the futures prices formatted on the NY stock exchange. A study on the co-movement of futures prices of agricultural products used especially in the production of bioenergy would be of great interest, while the role of crude oil prices seems to have had a great impact on those prices. Natanelov et al. [8] have made a similar effort, and, according to their results, co-movement is a dynamic concept, and economic and policy development may affect the relationship between commodities, while they have also shown that biofuel policy has a strong impact in the co-movement of crude oil and corn futures until the crude oil prices surpass a certain threshold.

The concept of excess co-movement among futures prices has been subject to extended study with the assistance of different methodologies. The most widely used methodology is cointegration implemented for different time periods and providing conflict results (Pindyck and Rodenberg [9], Natanelov et al. [8]). Confirmation of co-movement is based on the herd behavior of financial prices [9]. Ali et al. [7], with the assistance of the partial equilibrium model, attributed the behavior of the commodity prices to specific demand and supply conditions. On the other hand, Natanelov et al. [8] focused on price movements between crude oil futures and a series of agricultural commodities and gold futures by employing a comparative framework to identify changes in relationships over time. According to their findings, co-movement is validated as a dynamic concept, while policy development may reform the relationship between commodities and their determinants that are studied, that is, crude oil prices.

The present study is timely, given the particularities in the evolution of crude oil prices within the last few years. To be more specific, the global economic crisis led to extremely high values of crude oil prices in 2010, while since 2014 the crude oil prices have tended to be persistently low, a fact that may well lead to a high level of carbon emissions and limited substitution with renewable energy prices. The volatility of crude oil prices has a different impact in the short term rather than in the long term. In addition, a strand of literature developed on this specific issue focuses on the fact that the crude oil market has significant volatility spillover effects on non-energy commodity markets, which demonstrates its core position among commodity markets [10]. This impact and its implications for the substitution of crude oil with other renewable or non-renewable resources seems to affect the level of carbon emissions and vice versa [11].

Furthermore, the futures prices for each commodity reflect the market condition, as well as the agricultural policies implemented concerning their production, market conditions, assistant aid, or even energy policy that promotes their use to produce biomass.

The innovation of our study stands on the fact that we employ ARDL bounds cointegration to test the crude oil-corn prices and soybean-crude oil prices. The structure of the present work is organized as follows; Section 2 describes material and methods, Section 3 provides a brief literature review, Section 4 provides the results and a short discussion, and Section 5 concludes.

\section{Literature Review}

The energy-agricultural market interlinkages have become a subject of extended study within the last decade. The global food crises in 2007/08 and 2010/11, as well as negative environmental and social impacts of promoting biofuels, have given governments second thoughts regarding the promotion of biofuels. 
Since the outbreaks of biofuels industry, an abundance of manuscripts have focused on dependency between fossil fuel, biofuel, and feedstock prices [12-15]. In a few papers and due to data availability issues, the biofuel prices are ignored [2]. In those studies, ignoring biofuel prices generally relies on the hypothesis that a change in the food-fuel price relationship post the outbreak of the biofuels industry is related to the impact of biofuels.

In most of these studies, the analysis used is cointegration and/or estimation of a VECM, or one of its generalized nonlinear versions. For the case of US, cointegration is validated between agricultural prices and energy prices, while energy prices are considered to drive the feedstock prices [12,16,17] (Saghaian 2010; Serra et al. 2011a; Wixson and Katchova 2012). The works conclude that the interlinkages are attributed to the existence of biofuel markets. Only Zhang et al. [14] confirm no evidence of cointegration between energy and agricultural commodity prices. Furthermore, only Serra et al. (2011) [12] and Rajcaniova and Pokrivcak (2011) [18] confirm that biofuel markets may shape fossil fuel prices.

In general, in most cases it is concluded that energy prices drive long-run world agricultural price levels [2]. In global terms, Nazlioglu and Soytas [19] appraise the link between world crude oil prices, USD exchange rates, and a long list of world agricultural commodity prices. In addition, Nazlioglu [20] finds evidence of cointegration between corn, soybean, and wheat with oil prices, especially in recent years. In another work, Yu et al. [21], focusing on the relationship between crude oil and edible oil prices, find no evidence of energy prices driving food prices.

The methodology of autoregressive distributed lag models (ARDL models) has been employed in many works [22-24].

To be more specific, Cooke and Robles [22] confirm that recent increases in world corn, wheat, rice, and soybean prices are strongly affected by oil prices. Chen et al. [23] find evidence of positive short-run links between crude oil and grain prices, while Esmaeili and Shokoohi [24] investigate co-movement of world food prices, oil prices, and different macroeconomic variables. According to their findings, crude oil prices affect food prices only indirectly through the food production index.

Global data, with a time period including peaks of crude oil prices and persistent low prices with the assistance of ARDL cointegration approach, and the futures prices that are considered more informative than real prices, constitute the innovation of the present manuscript.

\section{Material and Methods}

The data employed in the present work are monthly futures prices of crude oil (CME NYMEX WTI Crude Oil Futures in US dollars per ton), corn, and soybeans (CME CBOT grain futures), derived by Bloomberg [25]. The study period is from July 1987 until February 2015. To account for the problem of comparing disparate price units, the data is indexed based on the price of August 1999 for each commodity.

Trend analysis of the data used for empirical investigation on the selected variables can be seen in Figures 1 and 2. To be more specific, Figure 1 illustrates the evolution of futures prices of crude oil, Figure 2 illustrates the evolution of corn futures prices, and, finally, Figure 3 illustrates the evolution of soybean futures prices.

Evidently, an increasing trend is validated for the case of crude oil prices with two structural breaks observed in 1999 and 2008 that will be further investigated with the assistance of a break unit root test.

On the other hand, for the case of the corn futures prices, Figure 2 presents a series of peaks that document the necessity of a break unit root test to examine the stationarity. Similar behavior can be seen for the case of soybean, since similar peaks are observed for the same time periods, as can be seen in Figure 3. 


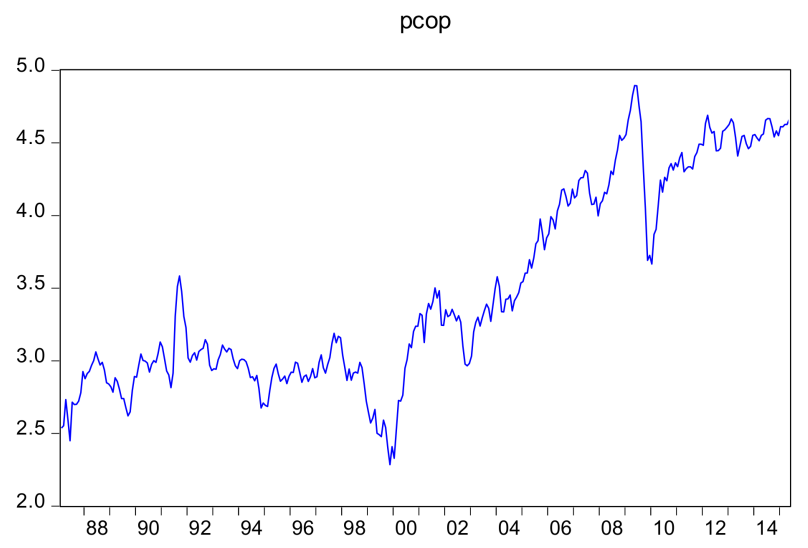

Figure 1. The evolution of futures crude oil prices in US dollars per barrel (in logarithmic form). Source: Bloomberg, [25].

PC2

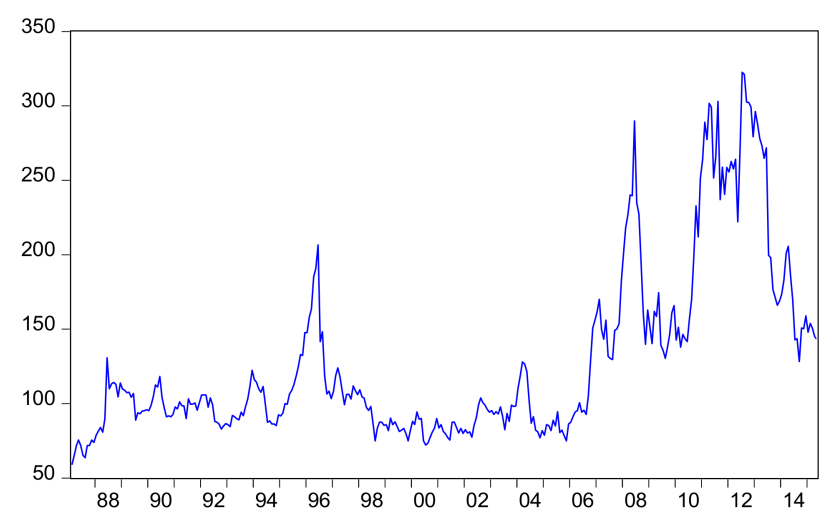

Figure 2. The evolution of futures corn prices in USD per ton (raw data). Source: Bloomberg, 2015 [25].

PSOY2

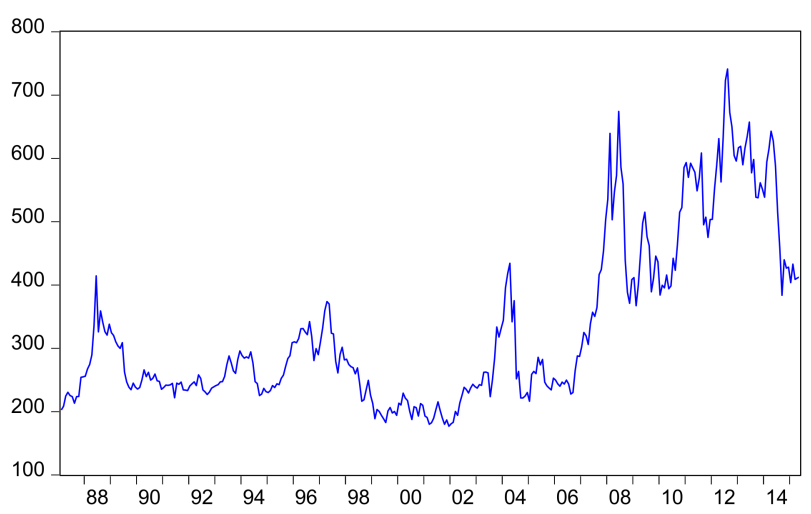

Figure 3. The evolution of futures soybean prices USD/ton (raw data). Source: Bloomberg [25].

\subsection{Model Specification}

We employed ARDL bounds cointegration process to estimate the relationship between the prices of the two agricultural commodities and crude oil prices. This relationship involves futures prices for soybean and corn, with crude oil prices as formatted in NY stock exchange. The advantage for the use of futures prices is that they represent not only the supply and demand conditions in the agricultural market but also a trend in the global economy (including economic crises, changes in exchange rates, 
etc.). Therefore, significant events that have an impact either on crude oil prices or on the agricultural commodities or changes in the major lines of energy policy (biofuels, issue of food security, and others) should be reflected in the estimated model in order for useful conclusions to come out.

The relationship to be examined for the case of corn is specified as follows:

$$
Z_{1 t}=f\left(P_{c o}, P_{t c}\right)
$$

In addition, in the case of soybean, the bivariate relationship to be surveyed is the following:

$$
Z_{3 t}=f\left(P_{\text {soy }}, P_{c}\right)
$$

\subsection{Theoretical Econometric Framework}

The methodology implemented is the ARDL bounds cointegration, given the limited data available [26]. Prior to the empirical investigation of co-movement among the variables under review with the assistance of ARDL cointegration approach, in order to check stationarity in the data, it is necessary to employ a unit root test. The unit root test used is the Augmented Dickey Fuller (ADF) break unit root test, given the structural breaks observed in the variables studied. The specific test involves a two-step procedure. In the first step the intercept, trend, and breaking variables are used to detrend the series with the assistance of ordinary least squares (OLS), and in the second step the detrended series are employed to test the existence of a unit root with the assistance of a modified Dickey-Fuller regression [27]. The first model may involve non-trending data with intercept break, trending data with intercept break, trending data with intercept and trend break, and finally trending data with trend break. The results refer either the trend specification (trend, intercept, or both) or to the break specification (trend, intercept, or both).

The problem of selecting an appropriate method of unit root test may well lead to misspecifications. For that reason, in the present manuscript, we have adopted the sequential procedure proposed by Shrestha and Chowdhury [28] in selecting the optimal method and model of the unit root test. The Shrestha-Chowdhury general-to-specific model selection procedure has been presented subtly in the work of Shrestha and Chowdhury [28].

The main objective of the particular test is to ensure that the time series employed are not I(2), a condition that implies robustness for the results derived by the ARDL bounds cointegration test.

Having validated the existence of cointegration, we estimate the Unrestricted Error Correction Model (UECM). The lag selection through which the data generating process is captured is based on the general-to-specific framework [29].

The ARDL model employed is, however, slightly modified in an appropriate way in order residual serial correlation and endogeneity problems to be corrected simultaneously [30]. The following UECM is used for our purpose.

The ARDL model employed is modified in an appropriate way in order for residual serial correlation and endogeneity problems to be corrected simultaneously [30]. The following UECM is used for our purpose.

$$
\ln Y_{t}=c_{1+}+c_{2} T+\beta_{1} \ln \left(X_{t}\right)+\sum_{i=1}^{p} \beta_{2} \Delta \ln \left(X_{c}\right)+\sum_{i=1}^{p} \beta_{3} \Delta \ln \left(Y_{t-1}\right)+u_{t}
$$

in which $Y_{t}$ demotes the dependent variable and $X_{t}$ denotes the independent variable in every individual case.

In Equation (3), we may identify the long term as well as the short-term parameters. To be more specific, $\beta_{1}$ represents the long-term parameter while rejecting the null hypothesis, and $\beta_{1}=0$ (equivalent to no cointegration) against the alternate, according to which $\beta_{1} \neq 0$ (which implies that the variables are cointegrated), The test for cointegration is based on the computed F-statistic compared to the values of the tabulated critical bounds. The upper critical bound (UCB) is employed 
under the condition that the regressors are $\mathrm{I}(1)$ or $\mathrm{I}(0)$, while the lower critical bound is used only under the condition that they are $\mathrm{I}(0)$. The potential results of the test are the following:

(1) If the $F$ statistic exceeds the Upper Critical Bound, cointegration is confirmed;

(2) In case the $F$ statistic is less than the lower Critical Value, the null hypothesis of no cointegration is confirmed;

(3) An area of uncertainty is determined within the two critical bounds, a case in which our decision relies on the lagged error correction term for a long run relationship.

The validity of the existence of a long run relationship allows the estimation of the error correction model (short run dynamics are surveyed), for which also sensitivity test, parameter stability, and goodness of fit using cumulative sum of squares of recursive residuals (CUSUM) is implemented.

The error correction model estimated for each bivariate relationship examined for the variables under review is provided by Equation (4).

$$
(1-L)\left[\begin{array}{c}
\ln Y_{t} \\
\ln (X)_{t}
\end{array}\right]=\left[\begin{array}{c}
\varphi_{1} \\
\varphi_{2}
\end{array}\right]+\sum_{i=1}^{p}(1-L)\left[\begin{array}{ccc}
\alpha_{11 i} & a_{12 i} & a_{13 i} \\
b_{21 i} & b_{22 i} & b_{23 i} \\
\delta_{31 i} & \delta_{32 i} & \delta_{33 i}
\end{array}\right]+\left[\begin{array}{c}
\beta \\
\gamma \\
\vartheta
\end{array}\right] E C M_{t-1}+\left[\begin{array}{c}
\eta_{1 i} \\
\eta_{2 i} \\
\eta_{3 i}
\end{array}\right]
$$

$L$ denotes the lag operator, and ECM denotes the error correction term generated by the cointegrating equation, while the $\eta$ terms are serially independent random error terms. The $F$ statistic for the parameters of first differences validates the short run causality, while on the other hand the statistical significance of $\varphi_{i}$ coefficients with the assistance of $t$ statistics provides evidence for the long run causality.

\section{Results-Discussion}

According to our findings provided in Table 1, with the assistance of a breakpoint ADF unit root test, all the variables employed are I(1), a result that allows us to bounds test.

Table 1. Results of breakpoint ADF unit root test.

\begin{tabular}{ccccc}
\hline Variables & Trend/Break Specification & $\boldsymbol{t}$-Statistic & Critical Values (5\%) & Break Date \\
\hline pc & Both/trend & -4.001 & -4.859 & November 1995 \\
pco & Both/both & -4.082 & -5.175 & January 2003 \\
psoy & Both/intercept & -4.129 & -4.859 & March 2005 \\
$\Delta$ pc & Both/Intercept & $-19.75^{* * *}$ & -4.859 & November 1987 \\
$\Delta$ pco & Both/Intercept & $-16.079 * *$ & -4.859 & April 2008 \\
$\Delta$ psoy & Both/Intercept & $-21.006^{* * *}$ & -4.859 & January 2007 \\
\hline
\end{tabular}

*** denotes reject of unit root hypothesis in $1 \%$ level of significance.

The second stage in our methodology involves the bounds testing to confirm or reject cointegration. The results are provided in the following Table 2.

Table 2. The results of bounds testing to cointegration.

\begin{tabular}{cc}
\hline Estimated Models & F-Statistics \\
\hline $\mathrm{F}_{\mathrm{c}}(\mathrm{pco} / \mathrm{pc})$ & $4.229^{* * *}$ \\
$\mathrm{~F}_{\mathrm{c}}(\mathrm{psoy} / \mathrm{pc})$ & $5.659^{* * *}$ \\
\hline
\end{tabular}

Critical Value Bounds for $10 \%, 5 \%, 2.5 \%$, and $1 \%$ are for Io Bound 2.44, 3.15, 3.88, and 4.81 , and for I1 Bound 3.28, $4.11,4.92$, and 6.03 , respectively. ${ }^{* * *}$ reject of no cointegration in $1 \%$ level of significance. 
The next Table 3 provides the estimated results on the long run relationships.

Table 3. Results of long run relationships.

\begin{tabular}{ccc}
\hline & Dependent Variable Pco & \\
\hline Corn-crude oil & Variable & Coefficient \\
& pc & $1.449^{* * *}$ \\
\hline & Dependent Variable Psoy & \\
Soybean-crude-oil & Variable & Coefficient \\
& pc & $1.640312^{* * *}$
\end{tabular}

*** denotes reject of null hypothesis of no statistic significance of the independent variable in $1 \%$ level of significance.

According to our findings, the results derived indicate the existence of interactions among agricultural commodities and crude oil prices. This is an expected result, and it validates the interactions of agricultural markets and crude oil markets in global terms. The specific results are interpreted as follows: given that corn is the major input for ethanol, a substitute for crude oil prices, the behavior of crude oil prices may well reflect the behavior of corn prices. To be more specific, high crude oil prices lead to high ethanol prices and therefore higher corn prices. Conversely, decreases in crude oil price will lead to a lower gasoline price, a lower ethanol price, and a lower breakeven corn price.

Furthermore, the results derived should be free from misspecification and autocorrelation or heteroscedasticity of the residuals. For that reason, all the tests concerning specification, autocorrelation, and heteroscedasticity tests are presented in Table 4. According to our findings, whiteness of the residuals for all the models, as well as no misspecification problems, were confirmed.

Table 4. Results of the diagnostic tests for the estimated models.

\begin{tabular}{ccc}
\hline & BG autocorrelation test & 0.334573 \\
\cline { 2 - 3 } Corn-Crude Oil Prices & BGP heter. test & 1.650531 \\
& RESET test & 1.2318 \\
\hline & BG autocorrelation test & 0.913924 \\
Soybean-Crude Oil Prices & BGP heter. test & 1.338892 \\
& RESET test & 0.45172 \\
\hline
\end{tabular}

The next step in our analysis involves the presentation of the short run dynamics of the error correction model estimated in order to examine the interactions among the corn prices and the crude oil prices in the short run and to highlight the differences with the results derived in the long run. These results are provided in Tables 5 and 6 . According to our findings, the results are not different from those derived in the long run. To be more specific, in the short term crude oil prices do not seem to have a statistically significant impact on the formation of a future's price of an agricultural product, i.e., corn. The return to the steady state is statistically significant, with a speed of $6 \%$ per month.

Table 5. Short run dynamics of the corn-crude oil prices relationship.

\begin{tabular}{ccccc}
\hline Regressor & Coefficient & St. Error & $\boldsymbol{t}$-Statistic & Probability \\
\hline $\mathrm{D}(\mathrm{PC} 1(-1))$ & -0.0125 & 0.0536 & -0.234 & 0.815 \\
$\mathrm{D}(\mathrm{PC} 1(-2))$ & 0.181 & 0.0532 & 3.406 & 0.0007 \\
$\mathrm{ECM}(-1)^{*}$ & -0.060 & 0.017 & -3.572 & 0.0004 \\
\hline \multicolumn{2}{c}{ Diagnostic Test Statistics; $\mathrm{R}_{\text {squared }}=0.05 ;$ Cointeq $=$ PC1 $-(1.4494 *$ PCOP1 -0.6718$)}$.
\end{tabular}


Table 6. Short run dynamics of the soybean-crude oil prices relationship.

\begin{tabular}{ccccc}
\hline Regressor & Coefficient & St. Error & $\boldsymbol{t}$-Statistic & Probability \\
\hline D(PSOY1(-1)) & -0.001270 & 0.053900 & -0.023555 & 0.9812 \\
D(PSOY1(-2)) & 0.138412 & 0.053465 & 2.588835 & 0.0101 \\
D(PSOY1(-3)) & -0.098150 & 0.053946 & -1.819404 & 0.0698 \\
ECM $(-1)^{*}$ & -0.056283 & 0.016705 & -3.369328 & 0.0008 \\
\hline
\end{tabular}

Diagnostic Test Statistics; Rsquared = 0.05; Cointeq = PSOY1 - (1.6403 * PCOP).

Regarding the last step in our analysis, the parameter stability of the estimated model is conducted with the assistance of the CUSUM of squared residual test.

Evidently, based on Figure 4, the graph of the corn-crude oil prices remains partially between the lines, a result indicating limited stability of the estimated coefficients for the period studied.

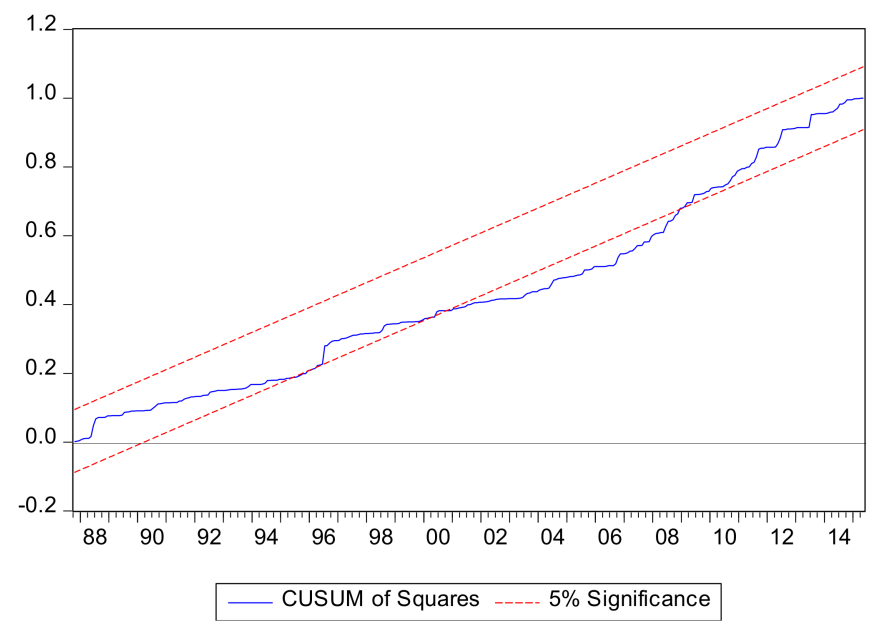

Figure 4. Results of CUSUM of squared residual test for crude oil-corn price relationship.

On the other hand, for the case of soybean crude oil prices relationship as illustrated in Figure 5, the CUSUM test of squared residuals confirms parameter stability.

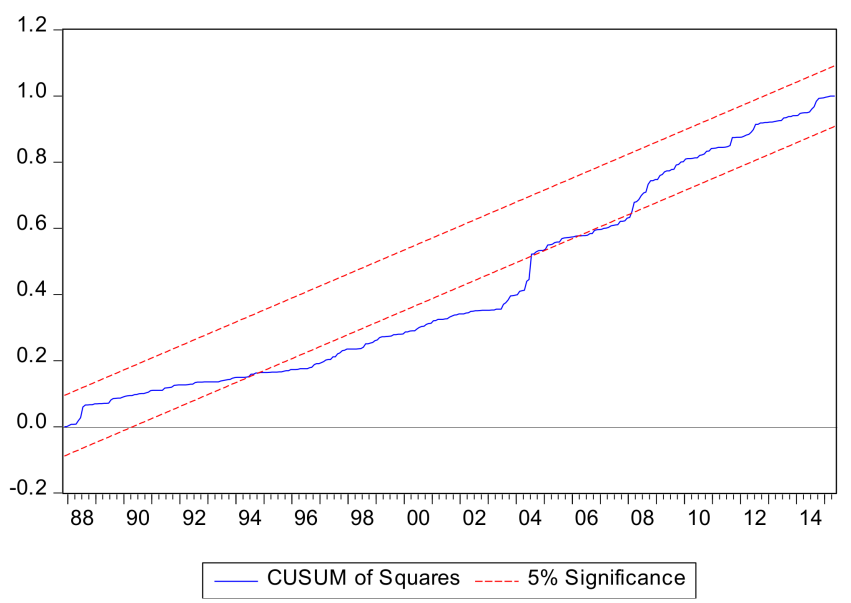

Figure 5. Results of CUSUM of squared residual test for crude oil-soybean price relationship.

Limited parameter stability is validated for the estimated model according to Figure 5. The findings based on our data indicate a long run relationship for both bivariate relationships, though in the short run no relationship is validated. This is an expected result given that the interaction 
between energy and agricultural market has evolved in the long run and not in the short run. This result is in line with that of Natanelov et al. [8], while the policies under the condition of the assumption of the long-run presence of a certain degree of linkage between energy markets and the market of food products that substitutes for other food products used as energy feedstock, and between food products used as energy feedstock and their substitutes for food exhibiting strong seasonality in production, would need to be flexible to be effective. The periodical shocks in the supply and demand of these agricultural commodities should be taken into consideration given that they may have a severe impact on the market interlinkages between different production periods.

The study of this relationship is important due also to the changes in biofuels industry. To be more specific, global biofuel production has been growing for the decade 2005-2015 with result that in the year 2014 ethanol production reached about 114 billion liters and biodiesel production reached about 30 billion liters [31]. The implementation of biofuel policies in global terms can expand the use of biofuels leading to a reduction in greenhouse gas emissions, along with limitation in the dependency on fossil fuel.

Though the interlinkages with the agricultural markets have led to high food prices, the simultaneous increase in feedstock prices has been harmful for biofuel competitiveness in the liquid fuels market, necessitating the need for subsidization and other protectionist policies. The solution to this problem is the promotion of second generation biofuels for which no food crops are used, since it will limit the competition for agricultural land and crops, reducing in turn the impact on agricultural prices. A final implication of our findings (the impact of energy prices on feedstock prices) can provide the food policy makers with a tool to forecast food prices and implement food policies with regard to the evolution of energy prices.

\section{Conclusions}

The present work provides an insight into the interaction between the crude oil futures market and the soybean and corn futures markets. The analysis of this relationship (co-movement) is based on the ARDL cointegration approach. The prices used were the futures and not the real market prices. The reason that we used the future prices is that they incorporate, by definition, all available information and thus are more efficient at identifying supply and demand shocks.

The selection of the specific agricultural commodities is related to their role in the production biofuels. An issue that is also worth mentioning is the great volatility observed within the last decade in the crude oil market. The confirmation of interlinkages among feed prices and energy prices may well interpret the transfer of instability from energy markets to food markets, a fact that has been particularly intensive since the 2010 due to the global biofuels industry boom. Therefore, it is necessary for the policies implemented to aim at limiting the linkages in order for the food crisis to be limited. The design of these policies can become plausible if it is studied adequately at what extent biofuels can limit the impact of extreme crude oil price changes relative to fossil fuels such as diesel or gasoline, and as a sequence to the prices of agricultural products used for the production of biodiesel. Copula modeling provides a plausible methodology for the study of this relationship, providing a solution to the global problem of interlinkages between energy and agricultural markets. [2].

Author Contributions: Eleni Zafeiriou conceived and designed the experiments. Eleni Zafeiriou and Garyfallos Arambatzis performed the experiments. All the authors analyzed the data. All the authors contributed reagents/materials/analysis tools; Eleni Zafeiriou wrote the paper.

Conflicts of Interest: The authors declare no conflict of interest. 


\section{References}

1. De Gorter, H.; Drabik, D.; Just, D.R. The Economics of Biofuel Policies: Impacts on Price Volatility in Grain and Oilseed Markets; Palgrave Studies in Agricultural Economics and Food Policy; Palgrave Macmillan: New York, NY, USA, 2015; p. 282, ISBN 9781137414847.

2. Serra, T.; Zilberman, D. Biofuel-related price transmission literature: A review. Energy Econ. 2013, 37, 141-151. [CrossRef]

3. Zafeiriou, E.; Arabatzis, G.; Tampakis, S.; Soutsas, K. The impact of energy prices on the volatility of ethanol prices and the role of gasoline emissions. Renew. Sustain. Energy Rev. 2014, 33, 87-95. [CrossRef]

4. Zafeiriou, E.; Karelakis, C. Income volatility of energy crops: The case of rapeseed. J. Clean. Prod. 2016, 122, 113-120. [CrossRef]

5. Zhang, Q.; Reed, M.R. Examining the Impact of the World Crude Oil Price on China's Agricultural Commodity Prices: The Case of Corn, Soybean, and Pork. In Proceedings of the 2008 Annual Meeting, Dallas, TX, USA, 2-6 February 2008.

6. Zilberman, D.; Kim, E.; Kirschner, S.; Kaplan, S.; Reeves, J. Technology and the future bioeconomy. Agric. Econ. 2013, 44, 95-102. [CrossRef]

7. Ai, C.R.; Chatrath, A.; Song, F. On the comovement of commodity prices. Am. J. Agric. Econ. 2006, 88, 574-588. [CrossRef]

8. Natanelov, V.; Alam, M.J.; McKenzie, A.M.; Van Huylenbroeck, G. Is there co-movement of agricultural commodities futures prices and crude oil? Energy Policy 2011, 39, 4971-4984. [CrossRef]

9. Pindyck, R.S.; Rotemberg, J.J. The excess co-movement of commodity prices. Econ. J. 1990, 100, 1173-1189. [CrossRef]

10. Ji, Q.; Fan, Y. How does oil price volatility affect non-energy commodity markets? Appl. Energy 2012, 89, 273-280. [CrossRef]

11. Apergis, N.; Payne, J.E. Renewable energy, output, $\mathrm{CO}_{2}$ emissions, and fossil fuel prices in Central America: Evidence from a nonlinear panel smooth transition vector error correction model. Energy Econ. 2014, 42, 226-232. [CrossRef]

12. Serra, T.; Zilberman, D.; Gil, J.M.; Goodwin, B.K. Nonlinearities in the U.S. corn-ethanolgasoline price system. Agric. Econ. 2011, 42, 35-45. [CrossRef]

13. Serra, T.; Gil, J.M. Biodiesel as a motor fuel price stabilization mechanism. Energy Policy 2012, 50, 689-698. [CrossRef]

14. Zhang, Z.; Lohr, L.; Escalante, C.; Wetzstein, M. Food versus fuel: What do prices tell us? Energy Policy 2010, 38, 445-451. [CrossRef]

15. Francisco, P.; Augusto, R.M. The Emergence of Biofuels and the Co-Movement between Crude Oil and Agricultural Prices; Department of Economics and Business, Universitat PompeuFabra: Barcelona, Spain, 2009.

16. Saghaian, S.H. The impact of the oil sector on commodity prices: Correlation or causation? J. Agric. Appl. Econ. 2010, 42, 477-485. [CrossRef]

17. Wixson, S.E.; Katchova, A.E. Price asymmetric relationships in commodity and energy markets. In Proceedings of the 123rd EAAE Seminar in Dublin, Ireland, 23-24 February 2012.

18. Pokrivcak, J.; Rajcaniova, M. Crude oil price variability and its impact on ethanol prices. Agric. Econ. Czech 2011, 57, 394-403. [CrossRef]

19. Nazlioglu, S.; Soytas, U. Oil price, agricultural commodity prices, and the dollar: A panel cointegration and causality analysis. Energy Econ. 2012, 34, 1098-1104. [CrossRef]

20. Nazlioglu, S. World oil and agricultural commodity prices: Evidence from nonlinear causality. Energy Policy 2011, 39, 2935-2943. [CrossRef]

21. Yu, L.; Wang, S.; Lai, K.K. Forecasting crude oil price with an EMD-based neural network ensemble learning paradigm. Energy Econ. 2008, 30, 2623-2635. [CrossRef]

22. Cooke, B.; Robles, M. Recent Food Prices Movements: A Time Series Analysis; IFPRI Discussion Papers 942; International Food Policy Research Institute (IFPRI): Washington, DC, USA, 2009.

23. Chen, S.T.; Kuo, H.I.; Chen, C.C. Modeling the relationship between the oil price and global food prices. Appl. Energy 2010, 87, 2517-2525. [CrossRef]

24. Esmaeili, A.; Shokoohi, Z. Assessing the effect of oil price on world food prices: Application of principal component analysis. Energy Policy 2011, 39, 1022-1025. [CrossRef] 
25. Bloomberg. Impact Report Update 2015. Available online: https:/ / data.bloomberglp.com/sustainability / sites/6/2016/04/16_0404_Impact_Report.Q12 (accessed on 10 April 2018).

26. Haug, A.A. Temporal aggregation and power of cointegration tests: A Monte Carlo study. Oxf. Bull. Econ. Stat. 2002, 64, 399-412. [CrossRef]

27. Vogelsang, T.J.; Perron, P. Additional tests for a unit root allowing for a break in the trend function at an unknown time. Int. Econ. Rev. 1998, 39, 1073-1100. [CrossRef]

28. Shrestha, M.B.; Chowdhury, K. ARDL Modelling Approach to Testing the Financial Liberalisation Hypothesis; Working Paper 05-15; Department of Economics, University of Wollongong: Wollongong, Australia, 2005.

29. Laurenceson, J.; Chai, C.H. Financial Reform and Economic Development in China; University of Queensland, Australia, Edward Elgar Publishing, Inc.: Oxford, UK, 2003, ISBN 1-84064-988-7.

30. Pesaran, M.H.; Shin, Y. An autoregressive distributed lag modelling approach to cointegration analysis. In Econometrics and Economic Theory in the 20th Century: The Ragnar Frisch Centennial Symposium; Strom, S., Ed.; Cambridge University Press: Cambridge, UK, 1999.

31. OECD-FAO. OECD-FAO Agricultural Outlook 2015; Organisation for Economic Cooperation and Development, and Food and Agricultural Organization of the United Nations: Rome, Italy, 2015.

(C) 2018 by the authors. Licensee MDPI, Basel, Switzerland. This article is an open access article distributed under the terms and conditions of the Creative Commons Attribution (CC BY) license (http:/ / creativecommons.org/licenses/by/4.0/). 